ARTICLE

DOI: $10.1038 / \mathrm{s} 41467-018-06204-2$

\title{
In-situ cross-linking strategy for efficient and operationally stable methylammoniun lead iodide solar cells
}

Xiaodong Li (iD 1, Wenxiao Zhang 1,2, Ying-Chiao Wang (10 1, Wenjun Zhang ${ }^{1,2}$, Hai-Qiao Wang ${ }^{1,2}$ \& Junfeng Fang ${ }^{1,2}$

Long-term operational stability is the foremost issue delaying the commercialization of perovskite solar cells (PSCs). Here we demonstrate an in-situ cross-linking strategy for operationally stable inverted $\mathrm{MAPbl}_{3}$ PSCs through the incorporation of a cross-linkable organic small molecule additive trimethylolpropane triacrylate (TMTA) into perovskite films. TMTA can chemically anchor to grain boundaries and then in-situ cross-link to a robust continuous network polymer after thermal treatment, thus enhancing the thermal, waterresisting and light-resisting properties of organic/perovskite films. As a result, the crosslinked PSCs exhibit 590-fold improvement in operational stability, retaining nearly $80 \%$ of their initial efficiency after continuous power output for $400 \mathrm{~h}$ at maximum power point under full-sun AM $1.5 \mathrm{G}$ illumination of Xenon lamp without any UV-filter. In addition, under moisture or thermal $\left(85^{\circ} \mathrm{C}\right)$ conditions, cross-linked TMTA-based PSCs also show excellent stability with over $90 \%$ of their initial or post burn-in efficiency after aging for over $1000 \mathrm{~h}$.

\footnotetext{
${ }^{1}$ Ningbo Institute of Materials Technology and Engineering, Chinese Academy of Sciences, Ningbo 315201, China. ${ }^{2}$ University of Chinese Academy of Sciences, Beijing 100049, China. Correspondence and requests for materials should be addressed to J.F. (email: fangjf@nimte.ac.cn)
} 
O rganic-inorganic metal halide perovskite solar cells (PSCs) are regarded as one of the most promising candidates in photovoltaic field due to their low-cost and high efficiency ${ }^{1-6}$. The device stability is a major bottleneck limiting the large scale development of $\mathrm{PSCs}^{7,8}$ since the certified power conversion efficiencies (PCEs) have exceeded 20\%9-13. The air (moisture) and thermal stability of PSCs have been significantly improved in past few years ${ }^{13-17}$. However, it is still far behind the requirement of commercialization as the most crucial issue of operational stability, namely the continuous power output of PSCs when subjected to realistic working conditions with light illumination and external load remains a challenge. Recently, through suppressing the degradation at charge transport layer (CTL), great improvement has been achieved in operationally stable PSCs by replacing the organic CTL with inorganic materials such as CuSCN or chlorine-caped $\mathrm{TiO}_{2}{ }^{18,19}$, which is the first but encouraging step toward operational stability. Studies have demonstrated that the stability issues of PSCs appear not only in CTL, but also in perovskite layer ${ }^{20}$. Up to now, the limited reports on long-term operational stability mainly aim at the CTLinduced degradation ${ }^{18,19}$ and rare reports are conducted from the point of perovskite layer. To further improve the operational stability, study on perovskite layer is necessary since the degradation of perovskite layer will impose limitation on the stability of PSCs, once the degradation caused by CTL is suppressed.

Solution-processed perovskite films usually have large grain boundaries (GBs), which are energetically unstable and easy to be attacked ${ }^{11,21}$. To improve the stability of perovskite films, one effective strategy is to cap these GBs with suitable protective materials ${ }^{22,23}$. Among them, small molecule additives that own weak interaction with GBs have been widely used, such as pyridine $^{24,25}$, ammonium chloride ${ }^{26}$, alkylphosphonic acid $\omega$ ammonium chlorides ${ }^{23}$, tertiary or quaternary hydrophobic alkyl ammonium cations ${ }^{11,27}$ and phenylalkylamine ${ }^{28,29}$. In addition, linear polymers of polyethyleneimine (PEI) and poly(4-vinylpyridine) (PVP) are also reported as additives for use in $\mathrm{PSCs}^{30,31}$, although it may lead to the precipitation in perovskite precursor solution due to their strong interaction with $\mathrm{PbI}_{2}$. The reported additives can passivate the defects and form a water-resisting layer at GBs to block the moisture penetration. As a result, the device efficiency and air stability is significantly improved. However, these reports mainly aim at the waterresisting property of additives to improve the moisture stability of PSCs; while their operational stability at maximum power point (MPP) is presented merely in time scale of several hours ${ }^{11,28,30}$ or even less (for example, 200s) ${ }^{24-27,31}$, which is far behind the requirement of commercial application. For operational stability, more factors, apart from moisture should be considered, including thermal, electric, light and so on ${ }^{8,13,16}$. Given the fact that cross-linked polymers usually possess excellent mechanical, thermal, dielectric and light-resisting properties ${ }^{32-34}$, it is envisaged that the cross-linking of organic additives should be a feasible method to improve the related properties of perovskite films and thus enhance the operational stability of PSCs.

Here, we develop an in-situ cross-linking strategy of organic additives to improve the operational stability of perovskite films. In our strategy, the cross-linkable monomer trimethylolpropane triacrylate (TMTA, Fig. 1a) is mixed into perovskite precursor solution and deposited on substrate to obtain perovskite films with TMTA, which can be further cross-linked through thermal treatment (Fig. 1b). As a result, highest efficiency approaching $20 \%$ is obtained in PSCs with TMTA. More importantly, the devices exhibit 590-fold improvement in operational stability relative to control devices, retaining nearly $80 \%$ (81.6\% from $J-V$ curve) of initial efficiency after continuous power output at MPP for $400 \mathrm{~h}$ under full-sun AM $1.5 \mathrm{G}$ illumination $\left(100 \mathrm{~mW} \mathrm{~cm}^{-2}\right)$.
Apart from operational stability, the air (relative humidity of $45-60 \%)$ and thermal $\left(85^{\circ} \mathrm{C}\right)$ stability are also greatly improved, retaining over $90 \%$ of the initial or post burn-in efficiency after aging for over $1000 \mathrm{~h}$. Different to most of the previous reports using ultraviolet-free white LED lamp ${ }^{18,35,36}$ or Xenon lamp with UV-filter ${ }^{19}$, our operational stability test is conducted under standard Xenon lamp (Newport Oriel Sol3A solar simulator) without any filter and a constant load $(0.84 \mathrm{~V})$ is continuously applied on the PSCs to simulate the realistic working conditions. In this work, we use methylammoniun lead iodide perovskite material $\left(\mathrm{MAPbI}_{3}\right)$ given its simple composition and easy fabrication. Compared with formamidinium lead iodide $\left(\mathrm{FAPbI}_{3}\right)$, the $\mathrm{MAPbI}_{3}$ device performance will not be greatly affected by the tetragonal-cubic phase transition due to their both black photoactive phase $\mathrm{s}^{37,38}$. Despite the above-mentioned advantages, no studies are reported about long-term operational stability in $\mathrm{MAPbI}_{3}$ until now. In addition, we adopt inverted device architecture in this work to avoid the use of high temperature sintering $\mathrm{TiO}_{2}$ in norm devices.

\section{Results}

In-situ cross-linking strategy. There are three unique advantages of TMTA: first, TMTA is a sticky liquid at room temperature (Supplementary Fig. 1a). During the crystallization of solid perovskite, the liquid TMTA will be automatically expelled to GBs without the interruption of crystal growth. Second, the carbonyl groups in TMTA allow weak interaction with $\mathrm{PbI}_{2}$ (Fig. 1c), making TMTA chemically anchor to GBs and passivate the defects $^{39}$, thus leading to improved device efficiency of over $20 \%$. Third, the three alkenyl groups in TMTA allow for the in-situ cross-linking polymerization (Fig. 1c) to process at GBs under moderate thermal conditions $\left(140^{\circ} \mathrm{C}\right)$, enhancing the thermal, water-resisting and light-resisting properties of perovskite film and thus improving operational stability of PSCs.

Fourier transform infrared spectroscopy (FTIR) is collected in $\mathrm{MAPbI}_{3}-\mathrm{TMTA}$ films before and after thermal treatment to verify the in-situ cross-linking of TMTA (Fig. 2a). Pure TMTA exhibit characteristic peaks of $-\mathrm{CH}_{3}\left(2970 \mathrm{~cm}^{-1}\right), \mathrm{C}=\mathrm{O}\left(1734 \mathrm{~cm}^{-1}\right)$ and $\mathrm{CH}_{2}=\mathrm{CH}$ groups. Among them, the vibration peaks of $\mathrm{CH}_{2}=\mathrm{CH}$ groups are in-depth studied, including the $\mathrm{C}-\mathrm{H}$ stretching vibration of $v_{=\mathrm{CH}}$ and $v_{=\mathrm{CH} 2}, \mathrm{C}-\mathrm{C}$ stretching vibration of $v_{\mathrm{C}=\mathrm{C}}$ and the $\mathrm{C}-\mathrm{H}$ bending vibration of $\gamma=\mathrm{CH} 2$. In $\mathrm{MAPbI}_{3}-\mathrm{TMTA}$ films, the vibrations peaks ascribed to $\mathrm{CH}_{2}=\mathrm{CH}$ all disappear after crosslinking at $140{ }^{\circ} \mathrm{C}$ (Fig. 2a and Supplementary Fig. 2a, 2b), including $v_{=\mathrm{CH}}\left(3110 \mathrm{~cm}^{-1}\right), v_{=\mathrm{CH} 2}\left(3043 \mathrm{~cm}^{-1}\right)$ and $\gamma_{=\mathrm{CH} 2}\left(903 \mathrm{~cm}^{-1}\right)$, while the peaks of $-\mathrm{CH}_{3}$ and $\mathrm{C}=\mathrm{O}$ still exist. This result indicates that TMTA in perovskite films indeed cross-link with each other via $\mathrm{CH}_{2}=\mathrm{CH}$ groups when annealed at $140^{\circ} \mathrm{C}$. Note that $\mathrm{N}-\mathrm{H}$ vibration in $\mathrm{MAPbI}_{3}$ also appears around $1640 \mathrm{~cm}^{-1}$ (Supplementary Fig. 2c) which overlaps with the $\mathrm{C}-\mathrm{C}$ vibration of $\mathrm{CH}_{2}=\mathrm{CH}$ in TMTA $\left(v_{\mathrm{C}=\mathrm{C}} 1640 \mathrm{~cm}^{-1}\right)^{40}$. The peak at $1640 \mathrm{~cm}^{-1}$ is greatly weakened in $\mathrm{MAPbI}_{3}$-TMTA films after cross-linking due to the polymerization of $\mathrm{CH}_{2}=\mathrm{CH}$ groups and the small peak around $1640 \mathrm{~cm}^{-1}$ should be ascribed to the $\mathrm{N}-\mathrm{H}$ vibration in $\mathrm{MAPbI}_{3}$ (magnified FTIR in Supplementary Fig. 2d). In addition, the liquid TMTA will become a solid after annealing at $140{ }^{\circ} \mathrm{C}$, strongly confirming its cross-linking under thermal conditions (Supplementary Fig. 1b).

Perovskite films characterization. In order to realize lowtemperature processed PSCs, inverted device architecture is adopted on the base of our previous works, with poly[3-(4methylamine carboxylbutyl)thiophene] (P3CT-N) ${ }^{41}$ and $[6,6]-$ phenyl $\mathrm{C}_{61}$ butyric acid methyl ester (PCBM) as hole and electron transport layer, respectively (Fig. 2b) ${ }^{42}$. $\mathrm{MAPbI}_{3}$ precursor 


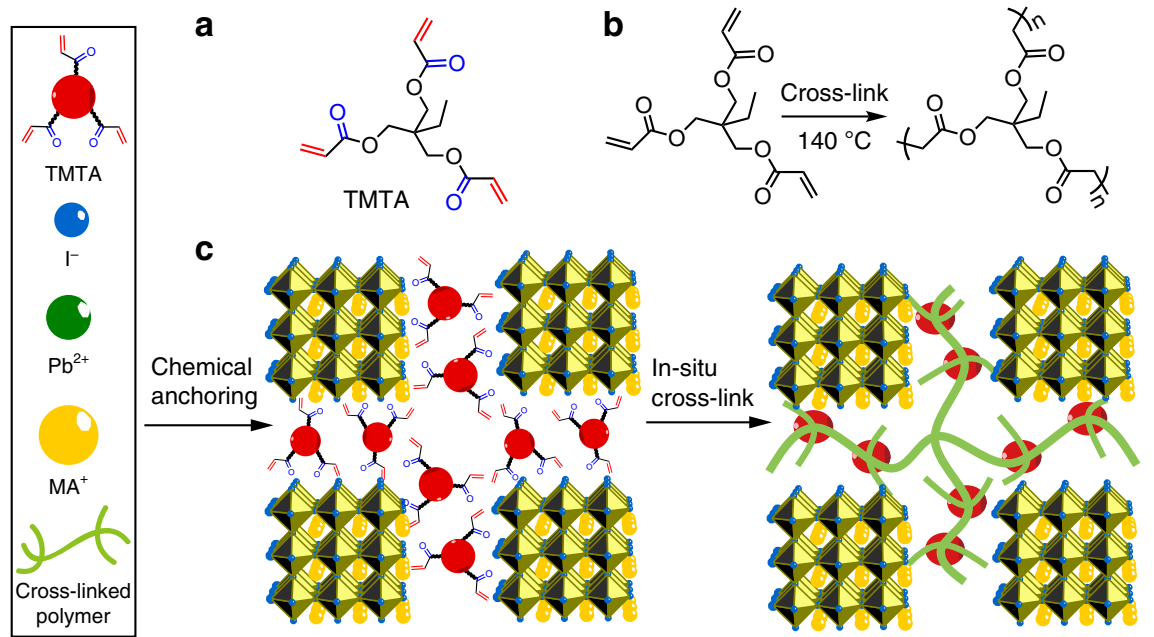

Fig. 1 Schematic illustrations of in-situ cross-linked organic/perovskite films. a Chemical structure of TMTA with marked carbonyl (blue) and alkenyl (red) groups. b Cross-linking polymerization of TMTA under thermal conditions. $\mathbf{c}$ Working mechanism of TMTA in PSCs: TMTA chemically anchors to the grain boundaries of $\mathrm{MAPbl}_{3}$ and then in-situ cross-links to a continuous network polymer
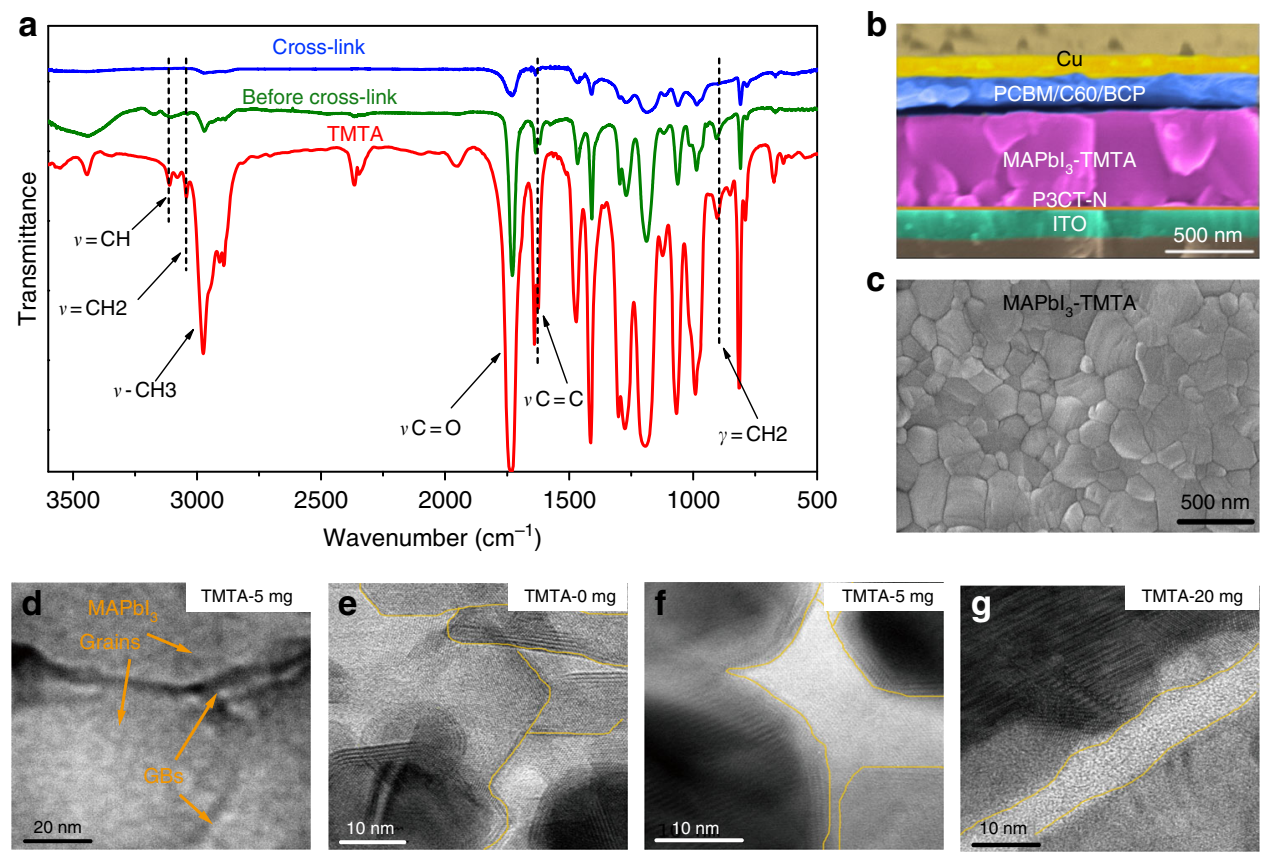

Fig. 2 FTIR and morphology characterization. a FTIR spectra of MAPbl ${ }_{3}$-TMTA films before (olive), after (blue) cross-linking and pure TMTA (red). The dash lines indicate the characteristic vibration peaks of TMTA. b Devices structure and cross-section SEM images of inverted PSCs used in our work. c Top-view SEM images of MAPbl ${ }_{3}$-TMTA films. $\mathbf{d}$ Low-magnification TEM image of MAPbl ${ }_{3}$-TMTA films. TMTA-5 mg indicates that the concentration of TMTA in $\mathrm{MAPb}_{3}$ precursor solution is $5 \mathrm{mg} \mathrm{mL}^{-1}$. e- $\mathbf{g}$ High resolution TEM of perovskite films: (e) $\mathrm{MAPbl}_{3}$; $(\mathrm{f}) \mathrm{MAPbl}_{3}-\mathrm{TMTA}\left(5 \mathrm{mg} \mathrm{mL}^{-1}\right.$ ), and $(\mathbf{g})$ $\mathrm{MAPbl}_{3}$-TMTA $\left(20 \mathrm{mg} \mathrm{mL}^{-1}\right)$. The yellow lines demarcate the grain boundary (GB) regions

solution with TMTA is deposited on ITO/P3CT-N substrate through typical anti-solvent method. Cross-sectional scanning electron microscopy (SEM) images reveal a $450 \mathrm{~nm}$ $\mathrm{MAPbI}_{3}-\mathrm{TMTA}_{\mathrm{T}}$ layer closely sandwiched between P3CT-N and PCBM interlayer (Fig. 2b). The $\mathrm{MAPbI}_{3}-\mathrm{TMTA}$ layer is vertically compact without obvious cracks or pinholes, which is beneficial to the vertical carriers transport. We also acquire the top-view SEM images of perovskite film as shown in Fig. 2c. $\mathrm{MAPbI}_{3}$-TMTA exhibits smooth and pinholes free morphology with large grains (average size $236 \mathrm{~nm}$ in Supplementary Fig. 3), similar to control $\mathrm{MAPbI}_{3}$ films due to the identical processing method (cross-sectional and top-view SEM of $\mathrm{MAPbI}_{3}$ in
Supplementary Fig. 4). As expected from previous studies $24,25,29$, $\mathrm{MAPbI}_{3}-\mathrm{TMTA}$ shows similar x-ray diffraction (XRD) patterns to $\mathrm{MAPbI}_{3}$ and no obvious shift in diffraction angle is observed (Supplementary Fig. 5), indicating that TMTA additive will not embed into crystal lattice of perovskite and can only exist at the GBs. We further use transmission electron miscroscopy (TEM) to investigate the nanoscale structure of perovskite films. To minimize damage to relatively soft $\mathrm{MAPbI}_{3}$ films ${ }^{43}$, the TEM samples are prepared by dropping perovskite solution directly onto carbon-coated TEM grids (details shown in Characterization section). Fig. 2d shows the lower magnification TEM image of cross-linked $\mathrm{MAPbI}_{3}-\mathrm{TMTA}$ films with obvious $\mathrm{MAPbI}_{3}$ grains 
a
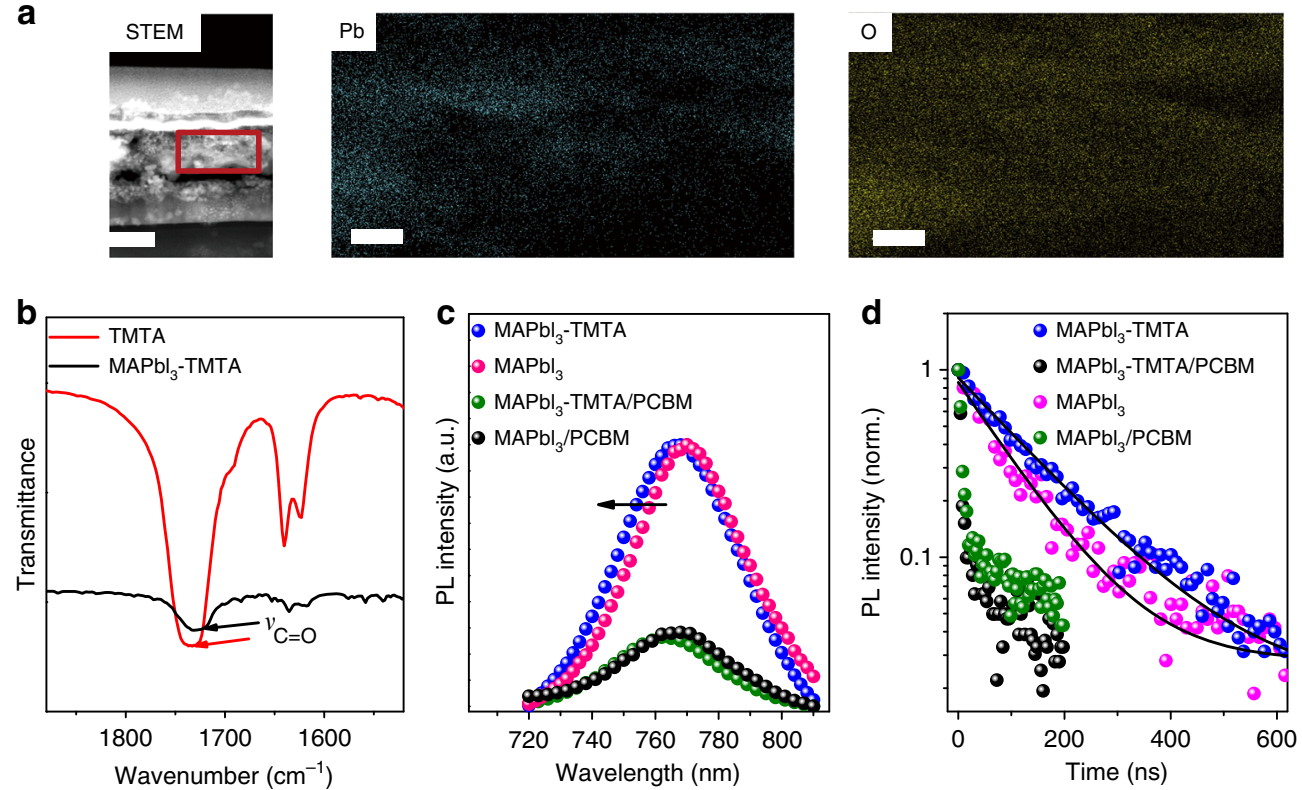

Fig. 3 TMTA distribution and photoluminescence (PL) characterization. a From left to right, scanning TEM (STEM, scale bar, $200 \mathrm{~nm}$ ) image and EDS mapping of $\mathrm{Pb}$ and $\mathrm{O}$ (scale bar, $50 \mathrm{~nm}$ ). The red line demarcates the EDS mapping area. $\mathbf{b}$ Enlarged FTIR spectra of MAPbl ${ }_{3}-\mathrm{TMTA}_{\mathrm{And}}$ pure TMTA; the arrows indicate the stretching vibration peak of $\mathrm{C}=\mathrm{O}$. $\mathbf{c}$ Steady-state $\mathrm{PL}$ spectra and $\mathbf{d}$ time-resolved PL decays of $\mathrm{MAPbl}_{3}, \mathrm{MAPbl}_{3} / \mathrm{PCBM}, \mathrm{MAPbl}_{3}-\mathrm{TMTA}$ and $\mathrm{MAPbl}_{3}$-TMTA/PCBM. The arrow indicates the blue-shifted PL peak in MAPbl ${ }_{3}-\mathrm{TMTA}$ film

and grain boundaries (GBs). High resolution TEM images are shown in Fig. 2e-g, focusing on the GB regions. The $\mathrm{MAPbI}_{3}$ films are fully crystalline without any obvious amorphous regions at GBs (Fig. 2e). The $\mathrm{MAPbI}_{3}-\mathrm{TMTA}$ films (Fig. 2f) clearly show that the amorphous walls, which can be ascribed to crosslinked TMTA, mainly exist among crystalline $\mathrm{MAPbI}_{3}$ grains ${ }^{43}$. And the amorphous TMTA walls become much clearer in $\mathrm{MAPbI}_{3}-\mathrm{TMTA}$ films with high TMTA concentration (Fig. 2g, more detailed views of HRTEM in Supplementary Fig. 6). This result strongly confirms that cross-linked TMTA indeed exists at GBs in perovskite films ${ }^{43}$.

Cross-sectional scanning TEM (STEM) and the corresponding energy dispersive X-ray spectroscopy (EDS) elemental mapping are conducted as shown in Fig. 3a. To in-situ characterize the vertical elemental distribution, STEM samples are prepared by spin-coating perovskite solution on ITO substrate using the same method with device fabrication. Then the sample is further processed using focused ion beam lift-out technique. The mapping area is focused on the perovskite layer, which is demarcated with red lines in Fig. 3a. In STEM-EDS mapping, $\mathrm{Pb}$ element represents $\mathrm{MAPbI}_{3}$ phase and $\mathrm{O}$ element represents TMTA phase. O element is observed throughout the $\mathrm{Pb}$-rich area, indicating the homogeneous distribution of TMTA. Combining with the results from HRTEM in Fig. 2, it can be concluded that TMTA exists at GBs in the whole perovskite films. To further investigate the existence states of TMTA in perovskite films, we acquire the enlarged FTIR spectra of pure TMTA and $\mathrm{MAPbI}_{3}-\mathrm{TMTA}$ as shown in Fig. 3b. The stretching vibration of $\mathrm{C}=\mathrm{O}\left(v_{\mathrm{C}=\mathrm{O}}\right)$ in pure TMTA appears at $1734 \mathrm{~cm}^{-1}$, while it shifts to $1725 \mathrm{~cm}^{-1}$ in $\mathrm{MAPbI}_{3}-\mathrm{TMTA}$. The shift to low wavenumber is indicative of the weakened $\mathrm{C}=\mathrm{O}$ bond as a consequence of the coordination between TMTA and MAPbI ${ }_{3}{ }^{10}$. Such coordination will help TMTA to anchor to the GBs and then passivate the possible defects.

Previous studies have confirmed that the defects at GBs will lead to the red-shift in photoluminescence (PL) spectra ${ }^{44}$. The control $\mathrm{MAPbI}_{3}$ film exhibits a PL peak at $770 \mathrm{~nm}$, while the
$\mathrm{MAPbI}_{3}-\mathrm{TMTA}$ film exhibits a PL peak at $766 \mathrm{~nm}$ (Fig. 3c). The blue-shifted PL peak indicates that TMTA can passivate the defects at GBs due to its coordination with $\mathrm{MAPbI}_{3}$ as confirmed in FTIR. In the presence of electron transport layer (PCBM), the $\mathrm{PL}$ of $\mathrm{MAPbI}_{3}-\mathrm{TMTA}$ is strongly quenched, indicating the efficient electron extraction between bulk perovskite and PCBM. Fig. 3d shows the time-resolved PL (TRPL) of perovskite films on ITO substrate. The longer carriers lifetime indicates better electronic quality in $\mathrm{MAPbI}_{3}-\mathrm{TMTA}(142 \mathrm{~ns})$ than in control $\mathrm{MAPbI}_{3}$ (101 ns). When PCBM is introduced, the lifetime sharply decreases to $5.6 \mathrm{~ns}$ in $\mathrm{MAPbI}_{3}-\mathrm{TMTA} / \mathrm{PCBM}$ and to $5.9 \mathrm{~ns}$ in $\mathrm{MAPbI}_{3} / \mathrm{PCBM}$, indicating the slightly faster electrons transfer at $\mathrm{MAPbI}_{3}-\mathrm{TMTA} / \mathrm{PCBM}$ interface.

Photovoltaic device performance. After successfully introducing TMTA into perovskite films, we investigate the photovoltaic performance of PSCs as shown in Fig. 4 and Supplementary Table 1. The PSCs with TMTA before cross-linking exhibit the highest efficiency of $20.22 \%$ (Fig. $4 \mathrm{a}$, inset: maximum power output of $19.8 \%$ ) with an open-circuit voltage $\left(V_{\text {oc }}\right)$ of $1.11 \mathrm{~V}$, short-circuit current density $\left(J_{\mathrm{sc}}\right)$ of $22.8 \mathrm{~mA} \mathrm{~cm}^{-2}$ and fill factor (FF) of $80.2 \%$ (Fig. $4 \mathrm{a}$ ), but their stability is poor (discussed in Long-term stability section below). Therefore, we start to pay more attention to the $\mathrm{MAPbI}_{3}-\mathrm{TMTA}$ devices after cross-linking in next investigation. The PSCs with TMTA after cross-linking yield a $V_{\mathrm{oc}}$ of $1.09 \mathrm{~V}, J_{\mathrm{sc}}$ of $22.7 \mathrm{~mA} \mathrm{~cm}^{-2}$ and $\mathrm{FF}$ of $78.2 \%$, resulting in an overall efficiency of $19.26 \%$ (Fig. 4b). The slight decrease in device efficiency after cross-linking may be caused by the insulation nature of cross-linked TMTA. The $\mathrm{MAPbI}_{3}$ devices exhibit a lower efficiency of $19.08 \%$ with $V_{\text {oc }}$ of $1.09 \mathrm{~V}, J_{\text {sc }}$ of 22.4 $\mathrm{mA} \mathrm{cm}{ }^{-2}$ and FF of $78.1 \%$ (Fig. 4c). As evident from the $J-V$ curves under forward and reverse scan, the hysteresis is discernable in control $\mathrm{MAPbI}_{3}$ devices, but it is negligible in devices with cross-linked TMTA (reverse efficiency of 19.01\%). Furthermore, the PSCs are probed at MPP under AM $1.5 \mathrm{G}$ illumination to determine their stabilized PCE. We obtain a stabilized 

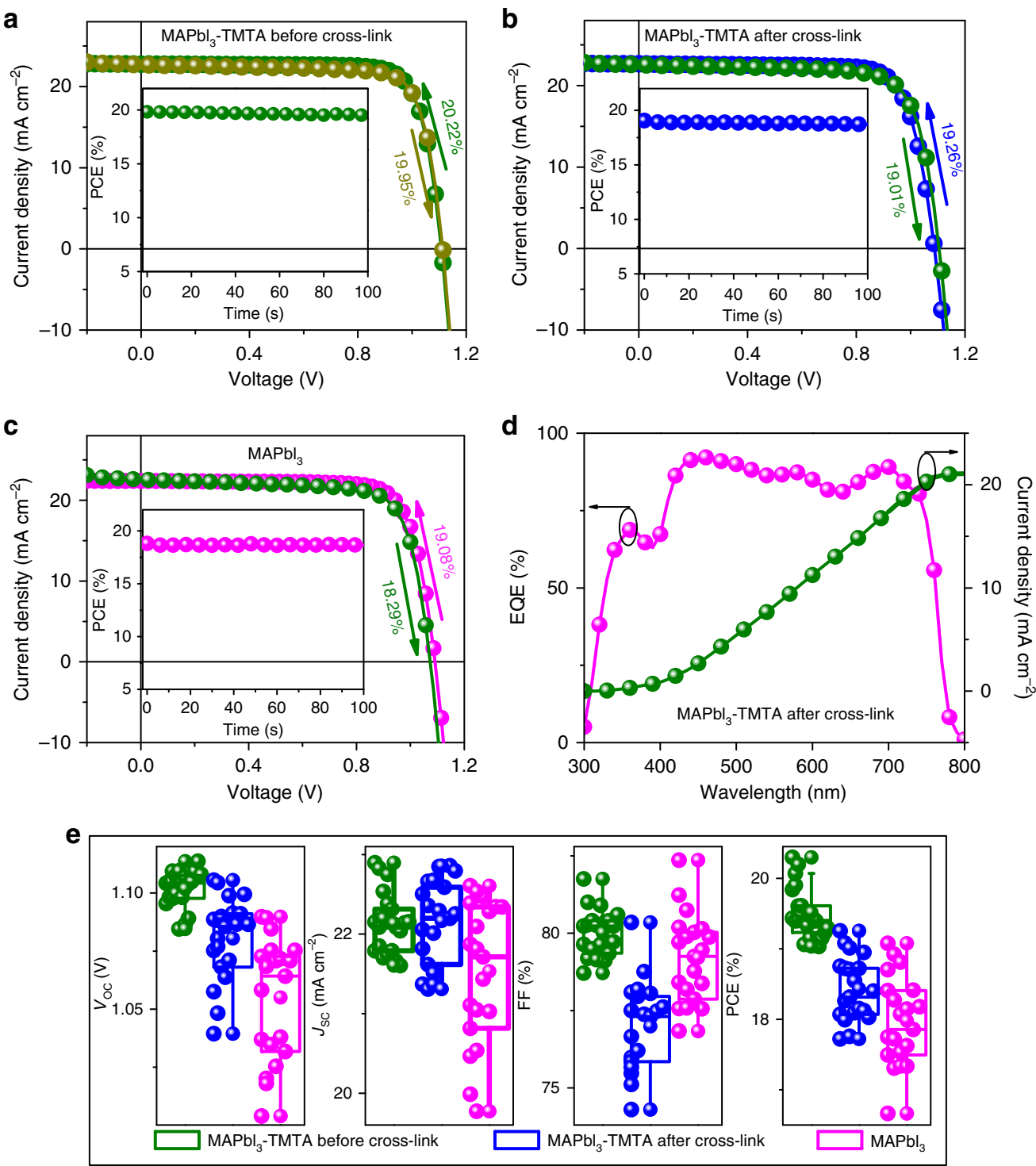

Fig. 4 Photovoltaic characterization. a J-V curves of $M \mathrm{APbl}_{3}-\mathrm{TMTA}$ PSCs before cross-linking; $\mathbf{b} J-V$ curves of MAPbl 3 -TMTA PSCs after cross-linking; c $J-V$ curves of control MAPb| ${ }_{3}$ PSCs. The arrows indicate the scan direction of $J-V$ measurement. Inset: the stabilized efficiencies of PSCs at MPP. $\mathbf{d}$ EQE as a function of monochromatic wavelength recorded for PSCs based on MAPbl 3 -TMTA after cross-linking. e The J-V metrics for 20 separated PSCs based on $\mathrm{MAPbl}_{3}$-TMTA before, after cross-linking and control MAPbl${ }_{3}$

power output of $19.1 \%$ and $18.8 \%$ in cross-linked $\mathrm{MAPbI}_{3}-\mathrm{TMTA}$ and control $\mathrm{MAPbI}_{3}$ devices respectively, agreeing closely with that obtained from $J-V$ curves. To understand the better performance in cross-linked $\mathrm{MAPbI}_{3}-\mathrm{TMTA}$ devices, we further study the recombination mechanism in PSCs through estimating the ideality factor $(n)^{18}$. As shown in Supplementary Fig. 7, we obtain $n$ of 1.78 and 1.50 in devices with $\mathrm{MAPbI}_{3}$ and cross-linked $\mathrm{MAPbI}_{3}-\mathrm{TMTA}$ by fitting the $V_{\mathrm{oc}}$ under different light intensity. The high $n$ value indicates the severer monomolecular recombination in control $\mathrm{MAPbI}_{3}$ devices, agreeing with the results obtained from PL and TRPL.

Figure $4 \mathrm{~d}$ shows the external quantum efficiency (EQE) spectra of our PSCs. The cross-linked $\mathrm{MAPbI}_{3}-\mathrm{TMTA}$ devices exhibit high EQE value (over $80 \%)$ in the visible light region $(410-740 \mathrm{~nm})$ and the integrated current densities closely agree with those extracted from $J-V$ curves. Fig. 4 e summarizes the statistical distribution of device parameters among 20 separated PSCs. The high performance is reproducible in devices with cross-linked TMTA and an average $V_{\mathrm{oc}}$ of $1.08 \pm 0.02 \mathrm{~V}, J_{\mathrm{sc}}$ of $22.2 \pm 0.52 \mathrm{~mA} \mathrm{~cm}^{-2}$ and FF of $77.0 \pm$
$1.4 \%$ is obtained (Supplementary Table1), resulting in an average efficiency of $18.43 \pm 0.45 \%$. For control $\mathrm{MAPbI}_{3}$ devices, the average efficiency is $17.98 \pm 0.63 \%$, with $V_{\text {oc }}$ of $1.06 \pm 0.03 \mathrm{~V}, J_{\text {sc }}$ of $21.5 \pm$ $0.89 \mathrm{~mA} \mathrm{~cm}^{-2}$, FF of $79.2 \pm 1.4 \%$.

Long-term stability. Apart from efficiency, we further examine the stability of PSCs under air, thermal and even operational conditions. In PSCs, the device stability is closely related to the GBs protection ${ }^{30}$ and ions (iodide) migration ${ }^{45-48}$ during operation. Previous study has confirmed that GBs existence is a major reason for $\mathrm{MAPbI}_{3}$ film decomposition in air as moisture can penetrate into the film bulk through GBs and thus accelerate $\mathrm{MAPbI}_{3}$ decomposition. In cross-linked $\mathrm{MAPbI}_{3}-\mathrm{TMTA}$ films, the GBs are blocked by cross-linked TMTA, suppressing moisture penetration. In addition, the contact angle of water on perovskite films with TMTA significantly increases from $52^{\circ}$ (before cross-linking) to $73^{\circ}$ after cross-linking due to the hydrophobic nature of TMTA (Supplementary Fig. 8), which 

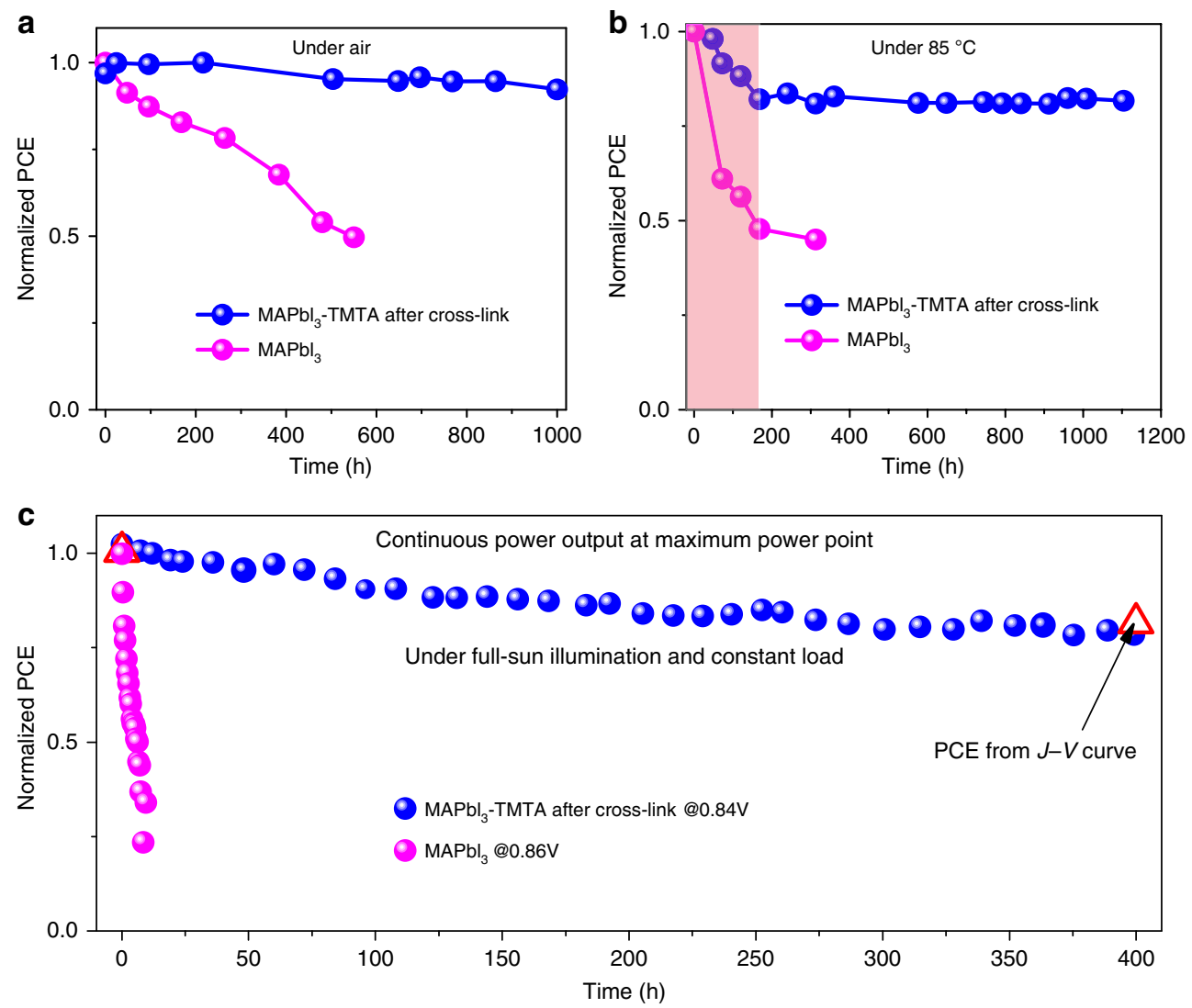

Fig. 5 Long-term stability. a Air stability of non-encapsulated PSCs based on cross-linked MAPbl ${ }_{3}-\mathrm{TMTA}_{\mathrm{A}}$ and control MAPbl $\mathrm{I}_{3}$. The devices are kept in air (relative humidity: 45-60\%) and measured regularly in glovebox filled with $\mathrm{N}_{2}$. b Thermal stability of PSCs based on cross-linked MAPbl ${ }_{3}-\mathrm{TMTA}_{\mathrm{T}}$ and control $\mathrm{MAPbl}_{3}$. The devices are kept on hotplate $\left(85^{\circ} \mathrm{C}\right)$ in glovebox and measured regularly. c Operational stability of non-encapsulated $\mathrm{MAPbl}{ }_{3}-\mathrm{TMTA}$ (after cross-linking) and control $\mathrm{MAPb}_{3}$ based PSCs. The devices are examined at maximum power point with a constant load (0.84 $\mathrm{V}, 0.86 \mathrm{~V}$ for $\mathrm{MAPbl}_{3}$-TMTA and $\mathrm{MAPbl}_{3}$ devices respectively) under continuous full-sun, AM $1.5 \mathrm{G}$ illumination in glovebox. Under this condition, the continuous power output is monitored in our PSCs. The red triangle is the devices efficiency obtained from $J-V$ curves. Note that the light source in the operational stability is Xenon lamp (Newport Oriel Sol3A solar simulator, $100 \mathrm{~mW} \mathrm{~cm}^{-2}$ ) without any UV filter calibrated by a reference solar cell (Newport) and that the external load $(0.84 \mathrm{~V})$ and $\mathrm{AM} 1.5 \mathrm{G}$ illumination is continuously applied on the PSCs except the calibration of light source

is much higher than that on control $\mathrm{MAPbI}_{3}$ films $\left(48^{\circ}\right)$, thus improving the device stability in air (XRD evolution of perovskite films exposed to air shown in Supplementary Fig. 9). Under air storage (relative humidity: 45-60\%), the nonencapsulated devices with cross-linked $\mathrm{MAPbI}_{3}-\mathrm{TMTA}$ show substantially enhanced stability, retaining $92.3 \%$ of their highest efficiency after $1000 \mathrm{~h}$ (Fig. 5a, non-normalized data in Supplementary Fig. 10). While, the devices before crosslinking maintain $57.6 \%$ of their initial efficiency merely after $550 \mathrm{~h}$ (Supplementary Fig. 11). Similarly, only $49.7 \%$ of the initial efficiency is maintained in control $\mathrm{MAPbI}_{3}$ devices under the same conditions (Fig. 5a). In addition, we have also examined the long-term stability of PSCs at high temperature ( $85^{\circ} \mathrm{C}$, in glove-box filled with $\mathrm{N}_{2}$, Fig. 5b). The cross-linked $\mathrm{MAPbI}_{3}$ devices exhibit obviously enhanced stability relative to control $\mathrm{MAPbI}_{3}$ devices. After early burn-in decay over the first $170 \mathrm{~h}^{16}$, cross-linked $\mathrm{MAPbI}_{3}$-TMTA devices show almost no degradation over the next $930 \mathrm{~h}$, stabilizing at over $98 \%$ of the post burn-in efficiency (over $80 \%$ of initial efficiency, non-normalized data in Supplementary Fig. 12). While $\mathrm{MAPbI}_{3}$ control devices only retain $45 \%$ of their initial efficiency merely after $300 \mathrm{~h}$.

Operational stability is of foremost concern in solar cells commercialization. For PSCs, the long-term operational stability has become imperative because the ions (iodide) migration in perovskite films under built-in field leads to the rapid degradation of PSCs ${ }^{49-53}$. As shown in Fig. 5c, despite high efficiency, the control $\mathrm{MAPbI}_{3}$ devices show poor operational stability, losing over $70 \%$ of their initial efficiency merely within $10 \mathrm{~h}$. Conventional strategy of using small molecule additives to passivate GBs is unable to block ions migration which may be caused by their nature of weakness and linear structure. Taking $\mathrm{MAbI}_{3}-\mathrm{TMTA}$ before cross-linking for example, the devices degrade rapidly at MPP (Supplementary Fig. 13), losing 65\% of the initial efficiency merely within $10 \mathrm{~h}$. Such instability has been associated with the iodide migration during operation ${ }^{52,53}$ and thus reaction at CTL/perovksite contacts $^{54}$ or even with metal electrode $\mathrm{f}^{50,55}$. To improve the operational stability, iodide migration should be suppressed especially at the $\mathrm{GBs}^{49}$, as GBs have much faster ions migration than the bulk, serving as an ion migration channel ${ }^{56,57}$. The introduction of previously reported liner polymer additive (PVP) shows limited improvement on the device degradation ${ }^{30}$. In devices with PVP (Supplementary Fig. 14), almost no degradation is observed at first $0.5 \mathrm{~h}(1800 \mathrm{~s})$ as $99 \%$ of the initial efficiency is retained. However, with time expended, the degradation starts to accelerate and only $60 \%$ of the initial efficiency is retained after $10 \mathrm{~h}$. Instead, we introduce robust and continuous network polymer at GBs through in-situ cross-linking of $\mathrm{MAPbI}_{3}-\mathrm{TMTA}$ film, establishing a blocker for iodide migration and thus significantly 
a

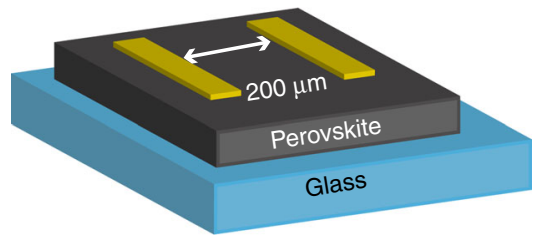

C

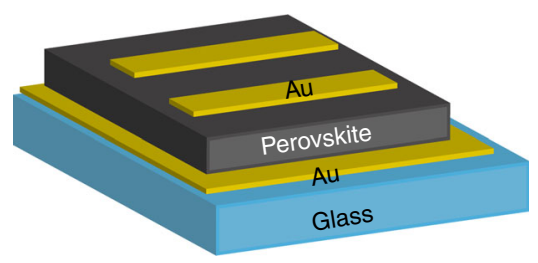

b

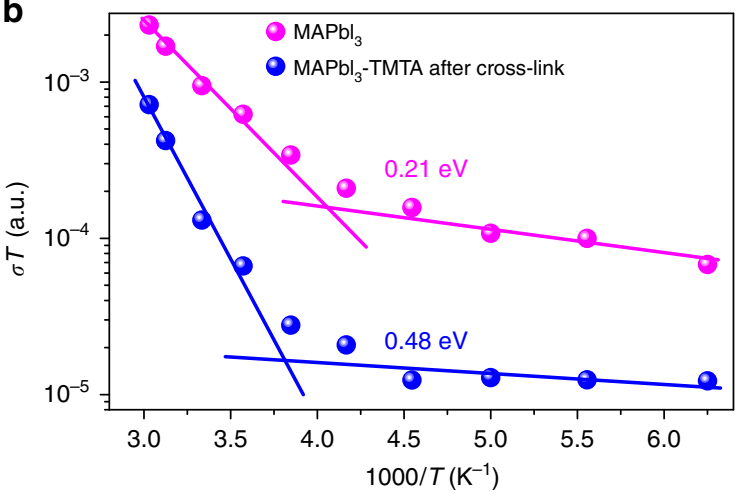

d

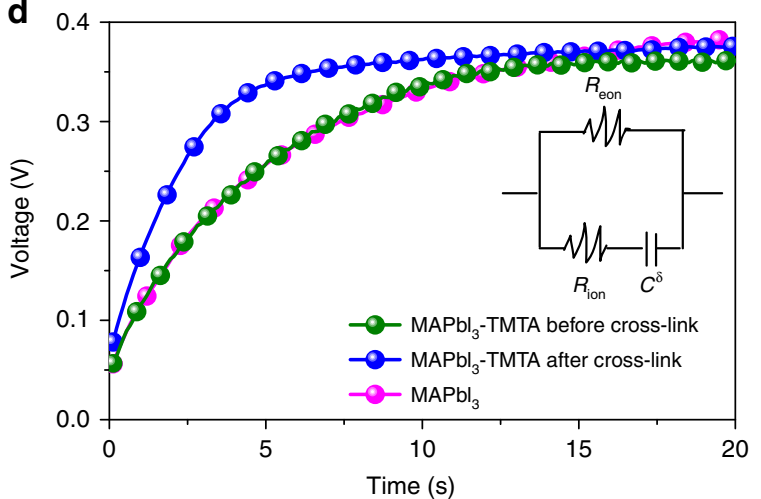

Fig. 6 lons migration in perovskite films. Activation energy represents how easily ions migrate. a Device structure used in activation energy measurement. b The temperature-dependent conductivity of perovskite films. Ions conductivity represents how fast ions migrate. c Device structure used in galvanostatic characterization. $\mathbf{d}$ Polarization curve in Au/perovskite/Au device measured in air by applying a constant current of $2 \mathrm{nA}$. The voltage response with time is recorded using Keithley 4200-SCS. Inset shows the equivalent circuit mimicking the galvanostatic characterization $\left(R_{\text {eon }}\right.$ electronic resistance, $R_{\text {ion }}$ ionic resistance, $C^{\delta}$ chemical capacitance)

improving the operational stability of PSCs under full-sun AM $1.5 \mathrm{G}$ illumination. The cross-linked $\mathrm{MAPbI}_{3}-\mathrm{TMTA}$ devices retain $78.5 \%$ ( $81.6 \%$ from $J-V$ curve, red triangle) of their initial efficiency after continuous power output at MPP for $400 \mathrm{~h}$ with a constant load of $0.84 \mathrm{~V}$ (the voltage at MPP from initial $J-V$ curve). The current density evolution during the operational stability test and the non-normalized data are shown in Supplementary Fig. 15. The efficiency distinction between stability test and $J-V$ curve originates from the device degradation during operation, thus leading to the voltage at MPP variation from initial $0.84 \mathrm{~V}$ to $0.82 \mathrm{~V}$ after $400 \mathrm{~h}$ (Supplementary Fig. 16). We define the time of $80 \%$ degradation as $\mathrm{T}_{80}$ to quantitatively evaluate the operational stability ${ }^{16}$. The cross-linked PSCs with TMTA exhibit a $\mathrm{T}_{80}$ of $390 \mathrm{~h}$, which is 590 -fold higher than that of control $\mathrm{MAPbI}_{3}$ devices $\left(\mathrm{T}_{80}\right.$ of $\left.0.66 \mathrm{~h}\right)$. Note that to simulate the realistic working conditions of PSCs, full-sun illumination and constant load $(0.84 \mathrm{~V})$ are continuously applied on the devices during the whole operational stability test. In addition, our operational stability test is conducted using standard Xenon lamp (Newport Oriel Sol3A solar simulator, $100 \mathrm{~mW} \mathrm{~cm}^{-2}$ ) without any UV-filter and the slight fluctuation in stability test should be caused by the calibration of light source. Apart from $\mathrm{MAPbI}_{3}$, the in-situ cross-linking strategy is also suitable in CsFAMAPbBr ${ }_{3-x} \mathrm{I}_{x}$ system. As shown in Supplementary Fig. 17, the CsFAMAPbBr ${ }_{3-x} \mathrm{I}_{x}$ devices with TMTA after cross-linking exhibit good operational stability even in humidity air without encapsulation (relative humidity: 30-60\%), retaining nearly $70 \%$ of the initial efficiency after continuous working at MPP for $100 \mathrm{~h}$. In-depth investigation on the efficiency and long-term stability of CsFAMAPbBr ${ }_{3-x} \mathrm{I}_{x}$ devices is beyond the scope of this work and will be the subject of future study.

Ions migration in perovskite films. We trace device degradation to the ions migration in perovskite films when PSCs are illuminated at MPP due to the existence of strong build-in field 50,52 We confirm the severe ions migration in $\mathrm{MAPbI}_{3}$ films through the measurement of activation energy $(\mathrm{Ea})$ and ions conductivity. $E$ a of ions conduction represents how easily ions migrate and can be obtained from the dependence of conductivity on temperature in $\mathrm{MAPbI}_{3}$ films ${ }^{58}$. We use lateral devices (Fig. 6a) in Ea measurement to weaken the electrons conduction and thus highlight the ions conduction proportion in total current ${ }^{52}$. The ions migration rate in solid is determined by $E$ a according to Nernst-Einstein equation: $\sigma(T)=\frac{\sigma 0}{T} \exp \left(\frac{E a}{k T}\right)$, where $k$ is the Boltzmann constant and $\sigma_{0}$ is a constant. Ea can be calculated from the slope of $\ln (\sigma T)-1 / k T^{58}$. During this measurement, a small electric field of $0.1 \mathrm{~V} \mathrm{~mm}^{-1}$ is adopted to suppress the poling effect ${ }^{52}$. Fig. $6 \mathrm{~b}$ shows the conductivity of perovskite films under different temperature. The $E \mathrm{a}$ in $\mathrm{MAPbI}_{3}$ film is fitted to be $0.21 \mathrm{eV}$, agreeing with previous reports ${ }^{51,52}$. The Ea in $\mathrm{MAPbI}_{3}-\mathrm{TMTA}$ after cross-linking is significantly increased to $0.48 \mathrm{eV}$, which is even twice larger than that in $\mathrm{MAPbI}_{3}$. In addition, the threshold temperature at which ions conduction starts to dominate the total current is also impressively increased in cross-linked $\mathrm{MAPbI}_{3}-\mathrm{TMTA}$ films. Ions start to migrate at $263 \mathrm{~K}$ in cross-linked $\mathrm{MAPbI}_{3}$-TMTA films, while the threshold temperature shifts to $246 \mathrm{~K}$ in $\mathrm{MAPbI}_{3}$ films. Both the larger 
$E \mathrm{a}$ and the higher threshold temperature indicate that ions migration is much more difficult in cross-linked $\mathrm{MAPbI}_{3}-\mathrm{TMTA}$ films than that in $\mathrm{MAPbI}_{3}{ }^{52}$.

On the other hand, ions conductivity represents how fast ions migrate in perovskite films ${ }^{59}$. We measure the ions conductivity of perovskite films at room temperature $(298 \mathrm{~K})$ using galvanostatic characterization, which is a typical method to separate ions and electrons conductivity in mixed-conductor ${ }^{59}$. In this measurement, a constant current of $2 \mathrm{nA}$ is applied on the $\mathrm{Au} /$ perovskite/Au device (Fig. 6c, equivalent circuit is shown in Fig. $6 \mathrm{~d}$ inset) and polarization curve (voltage response with time, Fig. 6d) is recorded using a semiconductor characterization system. Upon switching on the current $(i=2 \mathrm{nA})$, the voltage instantaneously reaches a value $\left(V_{0}\right)$. In this stage, both the electrons and ions contribute to the electrical resistance $\left(V_{0}=i^{*} \frac{R_{\text {eon }}^{*} R_{\text {ion }}}{R_{\text {en }}+R_{\text {ion }}}\right.$, where $R_{\text {eon }}$ and $R_{\text {ion }}$ are electronic resistance and ionic resistance, respectively $)^{59}$. With time increasing, ions are progressively blocked due to the formation of internal compositional gradient in perovskite films. As a result, the voltage also increases gradually until reaching a saturation value $(V s)$. In this saturated region, only electrons flow and contribute to electrical resistance $\left(V \mathrm{~s}=i \times R_{\text {eon }}\right)^{59}$. From $V \mathrm{~s}$, we can calculate the electrons conductivity $\left(\sigma_{\text {eon }}\right)$ and then obtain the ions conductivity $\left(\sigma_{\text {ion }}\right)$ when combining with $V_{0}$ (the calculated results are listed in Supplementary Table 2). The $\mathrm{MAPbI}_{3}$ films exhibit high $\sigma_{\text {ion }}$ of $0.909 \times 10^{-9} \mathrm{~S} \mathrm{~cm}^{-1}$, which is approximately 6-fold larger than the $\sigma_{\text {eon }}\left(0.159 \times 10^{-9} \mathrm{~S} \mathrm{~cm}^{-1}\right)$, indicating the non-negligible ions migration in perovskite films. Cross-linking is an effective method to suppress ions migration, which has been confirmed in polymeric electrolyte system ${ }^{60}$. The cross-linked $\mathrm{MAPbI}_{3}-$ TMTA films exhibit a much lower $\sigma_{\text {ion }}$ of $0.608 \times 10^{-9} \mathrm{~S} \mathrm{~cm}^{-1}$, which is decreased by $30 \%$ in comparison with that of $\mathrm{MAPbI}_{3}$-TMTA before cross-linking $\left(0.893 \times 10^{-9} \mathrm{~S} \mathrm{~cm}^{-1}\right)$. According to the results obtained in activation energy and ions conductivity measurement, it can be concluded that ions are not only much easier to migrate but also migrate much faster in $\mathrm{MAPbI}_{3}$ than cross-linked $\mathrm{MAPbI}_{3}-\mathrm{TMTA}$. Under internal field, the ions (iodide) will migrate toward and accumulate at cathode, thus accelerating the degradation of PSCs ${ }^{50}$. Using X-ray photoelectron spectroscopy (XPS in Supplementary Fig. 18), we confirm the accumulation of I element at interface between $\mathrm{BCP}$ and $\mathrm{Cu}$ in $\mathrm{MAPbI}_{3}$ devices, which is greatly suppressed in cross-linked $\mathrm{MAPbI}_{3}-\mathrm{TMTA}$ devices after operation at MPP. Basing on these findings, we conclude that the ions migration in $\mathrm{MAPbI}_{3}$ films is a major reason for the devices degradation. Our in-situ cross-linked $\mathrm{MAPbI}_{3}-\mathrm{TMTA}$ films can effectively suppress the ions migration through increasing the activation energy of ions migration and decreasing the ions conductivity, thus improving operational stability of PSCs.

\section{Discussion}

In summary, we demonstrate a strategy of in-situ cross-linking organic/ $\mathrm{MAPbI}_{3}$ films for operationally stable PSCs through the incorporation of cross-linkable TMTA additive. TMTA can chemically bond to GBs and passivate the defects, leading to highest efficiencies of over $20 \%$. Importantly, TMTA at GBs can be in-situ cross-linked to a robust polymer network after thermal treatment, serving as a protective layer and ions migration blocker, thus improving the thermal, water-resisting and lightresisting properties of perovskite films. The resulting PSCs exhibit 590 -fold improvement in operational stability relative to control $\mathrm{MAPbI}_{3}$ devices, retaining nearly $80 \%$ of the initial efficiency after continuous power output at MPP for $400 \mathrm{~h}$ with a constant load of $0.84 \mathrm{~V}$ under continuous full-sun, AM 1.5 G illumination (Xenon lamp, $100 \mathrm{~mW} \mathrm{~cm}^{-2}$ ). This is the first report of operationally stable $\mathrm{MAPbI}_{3}$ PSCs without any mixed-cations. In addition, the moisture or thermal $\left(85^{\circ} \mathrm{C}\right)$ stability is also improved, retaining over $90 \%$ of their initial or post burn-in efficiency after aging for over $1000 \mathrm{~h}$.

Our work highlights the role of perovskite layer on operationally stable PSCs and proposes a unique strategy to improve the stability of perovskite layer. Using this in-situ cross-linking strategy, various cross-linked polymers with different mechanical, thermal, dielectric, water-resisting or light-resisting properties can be introduced into perovskite layer in future, thus improving the related properties of organic/perovskite films, which may be an important approach to improve the stability of perovskite films. On the other hand, the stability issues of PSCs originate not only from perovskite layer, but also from the charge transport layer (CTL). In this work, we adopt inverted device architecture with all organic CTLs (P3CT and PCBM) since our main aim is at perovskite layer. Therefore, the CTL-induced degradation is inevitable (Supplementary Fig. 18). In future studies, the operational stability of PSCs can be further improved through the combination with CTL optimization, for example, the introduction of stable inorganic CTLs, such as $\mathrm{CuSCN}^{18}, \mathrm{Ta}^{\mathrm{W}} \mathrm{WO}_{x}{ }^{13}$ and chlorine-caped $\mathrm{TiO}_{2}{ }^{19}$.

\section{Methods}

Preparation of perovskite precursor solution. The pure TMTA is obtained from Aladdin (China). For $\mathrm{MAPbI}_{3}$ precursor solution, $1.45 \mathrm{M} \mathrm{PbI}_{2}$ (Alfa Aesar) and 1.45 M MAI are mixed together in anhydrous dimethylformamide/dimethylsulfoxide (4:1, volume ratio). For $\mathrm{MAPbI}_{3}-\mathrm{TMTA}$, TMTA is added into the precursor with a concentration of $5 \mathrm{mg} \mathrm{mL}^{-1}$.

Device fabrication. The glass/ITO substrate $(2 \mathrm{~cm} \times 2 \mathrm{~cm})$ is sequentially cleaned by ultrasonication in detergent, distilled water, acetone and isopropanol. The cleaned substrate is dried with $\mathrm{N}_{2}$ flow and then treated in $\mathrm{O}_{2}$ plasma for $2 \mathrm{~min}$. The P3CT-N solution ( $2 \mathrm{mg} \mathrm{mL}^{-1}$ in methanol) is deposited on ITO substrate in air through spin-coating at 4000 r.p.m for $60 \mathrm{~s}$, and then annealed at $100^{\circ} \mathrm{C}$ for 10 min. After depositing P3CT-N hole transporting layer, perovskite layer is deposited by a typical anti-solvent method in glovebox filled with $\mathrm{N}_{2}$. The perovskite precursor solution is spin-coated on ITO/P3CT-N at 4800 r.p.m. for 20 s. During spincoating, $300 \mu \mathrm{L}$ chlorobenzene is dropped on the center of the substrate $12 \mathrm{~s}$ prior to the end of the program. The substrate is then annealed at $60{ }^{\circ} \mathrm{C}$ for $2 \mathrm{~min}$ and $80^{\circ} \mathrm{C}$ for $5 \mathrm{~min}$ to form perovskite layer. For cross-linked $\mathrm{MAPbI}_{3}-\mathrm{TMTA}$, the perovskite film is further transfer to a pre-heated hot-plate and annealed at $140^{\circ} \mathrm{C}$ $10 \mathrm{~min}$ to promote the cross-linking of TMTA. After cooling down to room temperature, a PCBM solution ( $10 \mathrm{mg} \mathrm{mL}^{-1}$ in chlorobenzene) is spin-coated on perovskite layer at 2000 r.p.m. for $45 \mathrm{~s}$ to form electron transporting layer. Finally, the substrate is transferred into vacuum chamber; $40 \mathrm{~nm}$ C60, $8 \mathrm{~nm}$ BCP and 100 to $200 \mathrm{~nm} \mathrm{Cu}$ are thermally evaporated under high vacuum $\left(1 \times 10^{-4} \mathrm{~Pa}\right)$. The active area, as defined by the overlap of $\mathrm{Cu}$ and ITO, is $0.06 \mathrm{~cm}^{2}$.

Characterization. The $J-V$ characteristics are recorded using Keithley 2400 sourcemeter under the solar simulator (Newport Oriel Sol3A) with simulated AM 1.5 G illumination $\left(100 \mathrm{~mW} \mathrm{~cm}^{-2}\right)$. The light source is a $450 \mathrm{~W}$ xenon lamp calibrated by a standard Si reference solar cell (Newport, $91150 \mathrm{~V})$. Unless otherwise stated, The $J-V$ curves are all measured in glovebox at room temperature under forward scan (unless otherwise stated) from $1.2 \mathrm{~V}$ to $-0.2 \mathrm{~V}$ with dwell time of $50 \mathrm{~ms}$ (the delay between measurement points is $50 \mathrm{~ms}$ ). The EQE measurement is conducted in air using Newport quantum efficiency measurement system (ORIEL IQE 200TM) combined with a lock-in amplifier and $150 \mathrm{~W}$ xenon lamp. The light intensity at each wavelength is calibrated by one standard Si/Ge solar cell.

Fourier transform infrared spectroscopy (FTIR) samples are prepared by scraping the perovskite films off the substrate and then mixed with pre-dried $\mathrm{KBr}$ powder. FTIR spectra are recorded in transmittance mode using IR spectrometer instrument (Thermo, Nicolet 6700).

Top-view scanning electron microscope (SEM) images are recorded using field emission scanning electron microscope (Hitachi, S-4800) with an accelerating voltage of $8 \mathrm{kV}$. Cross-section SEM images are recorded with an accelerating voltage of $6 \mathrm{kV}$.

Transmission electron miscroscopy (TEM) images are recorded using JEOL2100, Japan. TEM samples are prepared by dropping perovskite solution $(0.2 \mathrm{M})$ onto TEM grids. Then the samples are rapidly transferred into chamber linked with vacuum pump for $10-20 \mathrm{~min}$. Then the samples are heated at $80^{\circ} \mathrm{C}$. For $\mathrm{MAPbI}_{3}-\mathrm{TMTA}$, the samples are further heated at $140^{\circ} \mathrm{C}$. Note that during the whole process, the TEM grids are in glass Petri dish to avoid the possible damage of grids. 
STEM-EDS mapping is conducted using Tecnai F20. The sample is spin-coated on ITO substrate similar to device fabrication. Then the MAPbI3-TMTA/ITO sample is further prepared using focused ion beam (Auriga) lift-out technique.

Photoluminescence (PL) spectra were recorded with a Fluorolog-Horiba fluorometer with excitation wavelength at $370 \mathrm{~nm}$ ). Time-resolved

photoluminescence (TRPL) decays are conducted with excitation wavelength at $370 \mathrm{~nm}$ and emission wavelength at $770 \mathrm{~nm}$.

Activation energy measurement of ions migration: The current is extracted at $150 \mathrm{~s}$ after the voltage is switched on. The measurement is conducted in a Lakeshore Probe Station under vacuum $\left(1.1 \times 10^{-4} \mathrm{~Pa}\right)$. The samples are placed on a copper substrate with temperature control by a heater and injected liquid He. A semiconductor characterization system (Keithley 4200-SCS) is used for the current measurement. During the measurement, we first cool the devices to $10 \mathrm{~K}$ for $1 \mathrm{~h}$ and then heat to objective temperature. Every objective temperature is stabilized for $5 \mathrm{~min}$ before the current record.

Ions conductivity measurement: The measurement is conducted in air by applying a constant current on Au/Perovskite/Au device (device area: $150 \mu \mathrm{m} \times$ $1000 \mu \mathrm{m})$. The voltage response with time is recorded using Keithley 4200-SCS.

Stability measurement. Dark stability is recorded by storing the non-encapsulated devices in air with controlled humidity $(45-60 \%)$. Before $J-V$ measurement, the PSCs are put into a vacuum chamber for 10-20 min to remove the moisture absorbed on surface.

Thermal stability is recorded by storing the non-encapsulated devices on a hot plate setting at $85^{\circ} \mathrm{C}$ in glovebox. The $J-V$ curves are measured after cooling the PSCs down to room temperature.

Operational stability: The $J-V$ curves are recorded first to verify the voltage at maximum power point (MPP). Then an external bias identical to the voltage at MPP in initial $J-V$ curves is applied on the devices. By monitoring the current density under AM $1.5 \mathrm{G}$ illumination, the operational stability test is obtained through multiplying the current density by the applied bias. The AM $1.5 \mathrm{G}$ illumination is achieved with a Xenon lamp (Newport Oriel Sol3A solar simulator) and periodically calibrated by a standard Si reference solar cell (Newport, $91150 \mathrm{~V}$ ). Note that during the whole MPP tracking, the external bias and AM $1.5 \mathrm{G}$ illumination is continuously applied on the PSCs except the calibration of light source. The temperature of PSCs during MPP tracking is monitored with an IR thermal gun.

\section{Data availability}

All relevant data are available from the authors on request.

Received: 26 April 2018 Accepted: 17 August 2018

Published online: 18 September 2018

\section{References}

1. Kojima, A., Teshima, K., Shirai, Y. \& Miyasaka, T. Organometal halide perovskites as visible-light sensitizers for photovoltaic cells. J. Am. Chem. Soc. 131, 6050-6051 (2009).

2. Zhang, W., Eperon, G. E. \& Snaith, H. J. Metal halide perovskites for energy applications. Nat. Energy 1, 16048 (2016).

3. Park, N.-G. Organometal perovskite light absorbers toward a $20 \%$ efficiency low-cost solid-state mesoscopic solar cell. J. Phys. Chem. Lett. 4, 2423-2429 (2013).

4. Gao, P., Grätzel, M. \& Nazeeruddin, M. K. Organohalide lead perovskites for photovoltaic applications. Energy Environ. Sci. 7, 2448-2463 (2014).

5. Chen, $\mathrm{H}$. et al. A solvent- and vacuum-free route to large-area perovskite films for efficient solar modules. Nature 550, 92 (2017).

6. Wang, Y. et al. High-efficiency flexible solar cells based on organometal halide perovskites. Adv. Mater. 28, 4532-4540 (2016).

7. Park, N.-G., Grätzel, M., Miyasaka, T., Zhu, K. \& Emery, K. Towards stable and commercially available perovskite solar cells. Nat. Energy 1, 16152 (2016).

8. Wang, Z., Shi, Z., Li, T., Chen, Y. \& Huang, W. Stability of perovskite solar cells: a prospective on the substitution of the A cation and $\mathrm{X}$ anion. Angew. Chem. Int. Ed. 56, 1190-1212 (2017).

9. Yang, W. S. et al. Iodide management in formamidinium-lead-halide-based perovskite layers for efficient solar cells. Science 356, 1376-1379 (2017).

10. Bi, D. et al. Polymer-templated nucleation and crystal growth of perovskite films for solar cells with efficiency greater than 21\%. Nat. Energy 1, 16142 (2016).

11. Zheng, X. et al. Defect passivation in hybrid perovskite solar cells using quaternary ammonium halide anions and cations. Nat. Energy 2, 17102 (2017).

12. Jiang, Q. et al. Enhanced electron extraction using $\mathrm{SnO}_{2}$ for high-efficiency planar-structure $\mathrm{HC}\left(\mathrm{NH}_{2}\right) 2 \mathrm{PbI}_{3}$-based perovskite solar cells. Nat. Energy 2, 16177 (2016)
13. Hou, Y. et al. A generic interface to reduce the efficiency-stability-cost gap of perovskite solar cells. Science 358, 1192-1197 (2017).

14. Chen, W. et al. Efficient and stable large-area perovskite solar cells with inorganic charge extraction layers. Science 350, 944-948 (2015).

15. You, J. et al. Improved air stability of perovskite solar cells via solutionprocessed metal oxide transport layers. Nat. Nanotechnol. 11, 75-81 (2015).

16. Wang, Z. et al. Efficient ambient-air-stable solar cells with 2D-3D heterostructured butylammonium-caesium-formamidinium lead halide perovskites. Nat. Energy 2, 17135 (2017).

17. Mei, A. et al. A hole-conductor-free, fully printable mesoscopic perovskite solar cell with high stability. Science 345, 295-298 (2014).

18. Arora, N. et al. Perovskite solar cells with $\mathrm{CuSCN}$ hole extraction layers yield stabilized efficiencies greater than $20 \%$. Science 358, 768-771 (2017).

19. Tan, H. et al. Efficient and stable solution-processed planar perovskite solar cells via contact passivation. Science 355, 722-726 (2017).

20. Lira-Cantú, M. Perovskite solar cells: stability lies at interfaces. Nat. Energy 2, 17115 (2017).

21. Wang, Q. et al. Scaling behavior of moisture-induced grain degradation in polycrystalline hybrid perovskite thin films. Energy Environ. Sci. 10, 516-522 (2017).

22. Huang, $\mathrm{S}$. et al. Enhancing the stability of $\mathrm{CH}_{3} \mathrm{NH}_{3} \mathrm{PbBr}_{3}$ quantum dots by embedding in silica spheres derived from tetramethyl orthosilicate in "waterless" toluene. J. Am. Chem. Soc. 138, 5749-5752 (2016).

23. Li, X. et al. Improved performance and stability of perovskite solar cells by crystal crosslinking with alkylphosphonic acid $\omega$-ammonium chlorides. Nat. Chem. 7, 703-711 (2015).

24. Noel, N. K. et al. Enhanced photoluminescence and solar cell performance via Lewis base passivation of organic-inorganic lead halide perovskites. ACS Nano 8, 9815-9821 (2014).

25. Abate, A. et al. Supramolecular halogen bond passivation of organic-inorganic halide perovskite solar cells. Nano. Lett. 14, 3247-3254 (2014).

26. Rong, Y. et al. Synergy of ammonium chloride and moisture on perovskite crystallization for efficient printable mesoscopic solar cells. Nat. Commun. 8, 14555 (2017)

27. Yang, S. et al. Functionalization of perovskite thin films with moisture-tolerant molecules. Nat. Energy 1, 15016 (2016).

28. Wang, F. et al. Phenylalkylamine passivation of organolead halide perovskites enabling high-efficiency and air-stable photovoltaic cells. Adv. Mater. 28, 9986-9992 (2016).

29. $\mathrm{Bi}, \mathrm{D}$. et al. High-performance perovskite solar cells with enhanced environmental stability based on amphiphile-modified $\mathrm{CH}_{3} \mathrm{NH}_{3} \mathrm{PbI}_{3}$. Adv. Mater. 28, 2910-2915 (2016).

30. Zuo, L. et al. Polymer-modified halide perovskite films for efficient and stable planar heterojunction solar cells. Sci. Adv. 3, el700106 (2017).

31. Zhao, Y. et al. A polymer scaffold for self-healing perovskite solar cells. Nat. Commun. 7, 10228 (2016).

32. Kaiser, T. Highly crosslinked polymers. Prog. Polym. Sci. 14, 373-450 (1989).

33. Banik, I., Bhowmick, A. K., Raghavan, S. V., Majali, A. B. \& Tikku, V. K. Thermal degradation studies of electron beam cured terpolymeric fluorocarbon rubber. Polym. Degrad. Stab. 63, 413-421 (1999).

34. Decker, C. \& Zahouily, K. Photodegradation and photooxidation of thermoset and UV-cured acrylate polymers. Polym. Degrad. Stab. 64, 293-304 (1999).

35. Domanski, K., Alharbi, E. A., Hagfeldt, A., Grätzel, M. \& Tress, W. Systematic investigation of the impact of operation conditions on the degradation behaviour of perovskite solar cells. Nat. Energy 3, 61-67 (2018).

36. Saliba, M. et al. Incorporation of rubidium cations into perovskite solar cells improves photovoltaic performance. Science 354, 206-209 (2016).

37. Zhang, H. et al. Photovoltaic behaviour of lead methylammonium triiodide perovskite solar cells down to $80 \mathrm{~K}$. J. Mater. Chem. A 3 11762-11767 (2015).

38. Quarti, C. et al. Structural and optical properties of methylammonium lead iodide across the tetragonal to cubic phase transition: implications for perovskite solar cells. Energy Environ. Sci. 9, 155-163 (2016).

39. $\mathrm{Wu}, \mathrm{Z}$. et al. Improved efficiency and stability of perovskite solar cells induced by $\mathrm{C}=\mathrm{O}$ functionalized hydrophobic ammonium-based additives. Adv. Mater. 30, 1703670 (2018).

40. Jeon, N. J. et al. Solvent engineering for high-performance inorganic-organic hybrid perovskite solar cells. Nat. Mater. 13, 897-903 (2014).

41. Li, X. et al. Improving efficiency and reproducibility of perovskite solar cells through aggregation control in polyelectrolytes hole transport layer. ACS Appl. Mater. Interfaces 9, 31357-31361 (2017).

42. Li, X. et al. Polyelectrolyte based hole-transporting materials for high performance solution processed planar perovskite solar cells. J. Mater. Chem. A 3, 15024-15029 (2015).

43. Zong, Y. et al. Continuous grain-boundary functionalization for highefficiency perovskite solar cells with exceptional stability. Chem 4, 1404-1415 (2018). 
44. Shao, Y., Xiao, Z., Bi, C., Yuan, Y. \& Huang, J. Origin and elimination of photocurrent hysteresis by fullerene passivation in $\mathrm{CH}_{3} \mathrm{NH}_{3} \mathrm{PbI}_{3}$ planar heterojunction solar cells. Nat. Commun. 5, 5784 (2014).

45. Bi, E. et al. Diffusion engineering of ions and charge carriers for stable efficient perovskite solar cells. Nat. Commun. 8, 15330 (2017).

46. Haruyama, J., Sodeyama, K., Han, L. \& Tateyama, Y. First-principles study of ion diffusion in perovskite solar cell sensitizers. J. Am. Chem. Soc. 137, 10048-10051 (2015).

47. Delugas, P., Caddeo, C., Filippetti, A. \& Mattoni, A. Thermally activated point defect diffusion in methylammonium lead trihalide: anisotropic and ultrahigh mobility of iodine. J. Phys. Chem. Lett. 7, 2356-2361 (2016).

48. Xiao, Z. et al. Giant switchable photovoltaic effect in organometal trihalide perovskite devices. Nat. Mater. 14, 193-198 (2014).

49. Yuan, Y. \& Huang, J. Ion migration in organometal trihalide perovskite and its impact on photovoltaic efficiency and stability. Acc. Chem. Res. 49, 286-293 (2016).

50. Guerrero, A. et al. Interfacial degradation of planar lead halide perovskite solar cells. ACS Nano 10, 218-224 (2015).

51. Eames, C. et al. Ionic transport in hybrid lead iodide perovskite solar cells. Nat. Commun. 6, 7497 (2015).

52. Xing, J. et al. Ultrafast ion migration in hybrid perovskite polycrystalline thin films under light and suppression in single crystals. Phys. Chem. Chem. Phys. 18, 30484-30490 (2016).

53. Domanski, K. et al. Migration of cations induces reversible performance losses over day/night cycling in perovskite solar cells. Energy Environ. Sci. 10, 604-613 (2017).

54. Carrillo, J. et al. Ionic reactivity at contacts and aging of methylammonium lead triiodide perovskite solar cells. Adv. Energy Mater. 6, 1502246 (2016).

55. Kato, Y. et al. Silver iodide formation in methyl ammonium lead iodide perovskite solar cells with silver top electrodes. Adv. Mater. Interfaces 2, 1500195 (2015).

56. Yun, J. S. et al. Critical role of grain boundaries for ion migration in formamidinium and methylammonium lead halide perovskite solar cells. $A d v$. Energy Mater. 6, 1600330 (2016)

57. Shao, Y. et al. Grain boundary dominated ion migration in polycrystalline organic-inorganic halide perovskite films. Energy Environ. Sci. 9, 1752-1759 (2016).

58. Bischoff, C., Schuller, K., Beckman, S. P. \& Martin, S. W. Non-Arrhenius ionic conductivities in glasses due to a distribution of activation energies. Phys. Rev. Lett. 109, 075901 (2012).

59. Yang, T.-Y., Gregori, G., Pellet, N., Grätzel, M. \& Maier, J. The significance of ion conduction in a hybrid organic-inorganic lead-iodide-based perovskite photosensitizer. Angew. Chem. Int. Ed. 54, 7905-7910 (2015).

60. Kim, S. R., Parvez, M. K., In, I., Lee, H. Y. \& Park, J. M. Novel photocrosslinkable polymeric electrolyte system based on poly(ethylene glycol) and trimethylolpropane triacrylate for dye-sensitized solar cell with long-term stability. Electrochim. Acta 54, 6306-6311 (2009).

\section{Acknowledgements}

This work was supported by National Natural Science Foundation of China (51773213, 61474125), China Postdoctoral Science Foundation funded project (2017M610380), Key Research Program of Frontier Sciences, CAS (QYZDB-SSW-JSC047), K. C. Wong Education Foundation (rczx0800), Zhejiang Province Science and Technology Plan (2018C01047) and National Youth Top-notch Talent Support Program.

\section{Author contributions}

J.F. conceived the idea and supervised the whole project. X.L. designed and participated in all the experimental sections. Wenxiao Zhang and Y.-C.W. carried out the SEM, TEM and FTIR measurements. Wenjun Zhang and H.-Q.W. carried out the PL and TRPL characterization and helped analyze the results. X.L. and J.F. co-wrote the paper.

\section{Additional information}

Supplementary Information accompanies this paper at https://doi.org/10.1038/s41467 018-06204-2.

Competing interests: The authors declare no competing interests.

Reprints and permission information is available online at http://npg.nature.com/ reprintsandpermissions/

Publisher's note: Springer Nature remains neutral with regard to jurisdictional claims in published maps and institutional affiliations.

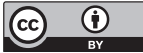

Open Access This article is licensed under a Creative Commons Attribution 4.0 International License, which permits use, sharing, adaptation, distribution and reproduction in any medium or format, as long as you give appropriate credit to the original author(s) and the source, provide a link to the Creative Commons license, and indicate if changes were made. The images or other third party material in this article are included in the article's Creative Commons license, unless indicated otherwise in a credit line to the material. If material is not included in the article's Creative Commons license and your intended use is not permitted by statutory regulation or exceeds the permitted use, you will need to obtain permission directly from the copyright holder. To view a copy of this license, visit http://creativecommons.org/ licenses/by/4.0/.

(C) The Author(s) 2018 